\title{
La cerámica de "Cuerda Seca" del antiguo convento de San Francisco de Asís de las Palmas de Gran Canaria
}

\author{
Elena Sosa Suárez
}

Arqueóloga

\section{Resumen}

En el año 1992 se realizó la excavación arqueológica del solar en que estuvo ubicado el antiguo Convento de San Francisco de Asís de Las Palmas de Gran Canaria. La importancia de esta intervención radicó en que se trataba de un edificio fundado a finales del siglo XV, en fechas próximas a la conquista de la isla por la Corona Castellana.

Entre el abundante material exhumado, de procedencias y cronologías diversas, presentamos en las siguientes páginas los resultados del estudio sobre una serie concreta: la de "cuerda seca".

La escasez de documentación que existía al respecto en el ámbito canario nos llevó a profundizar en su origen más remoto, a descubrir el proceso técnico utilizado en su elaboración, así como investigar cuál o cuáles eran los posibles centros de producción que elaboraba este tipo cerámico, y en qué fechas.

Gracias a los estudios precedentes y a algunos hallazgos arqueológicos paralelos, podemos fechar nuestras piezas entre finales del siglo XV y mediados del XVI, así como asignarles una procedencia sevillana.

Palabras clave: Cerámica, cuerda seca, arqueología histórica, Canarias, siglo XV

\begin{abstract}
In 1992 an archaeological excavation was carried out where the old Convent of San Francisco de Asís was once situated in Las Palmas de Gran Canaria. It was founded at the end of the XV century, when the Castilian Crown had finished the conquest of the Island.

Among the abundant exhumed material of the very diverse origins and chronologies, the results of the study on one concrete series "cuerda seca" will be dealt with in the following pages.

Due to the little documentation that exists in this respect in the Canary Islands, we had to explore their remote origin in order to discover the technical process used in their elaboration, as well as to investigate which were the possible production centres that elaborated this ceramic type, and in what dates.

Thanks to parallel studies and discoveries, we can date our pieces at the end of the XV and the first half of the XVI centuries, and even assign a Sevillian origin to our pieces.
\end{abstract}

KEY WORDS: Ceramics, Morisco ware, Historical Archaeology, Canary Islands, XV century.

\section{INTRODUCCIÓN}

El antiguo convento de San Francisco de Asis de Las Palmas de Gran Canaria es uno de los enclaves históricos más importantes de la Isla, por ser la primera fundación capitalina de la orden franciscana a raíz de la Conquista en 1483. Construido en el último tercio del siglo XV y hoy desaparecido, quedan como testigos los que un día fueran su iglesia y el campanario.
En el año 1992, el Servicio de Arqueología del Museo Canario, realizó los sondeos arqueológicos del solar donde estuvo ubicado. Si bien se hizo un estudio exhaustivo de documentos por parte de los asesores históricos de la excavación, a la hora de analizar los restos cerámicos que salieron a la luz en dicho trabajo de campo, nos encontramos con un yacimiento alterado por diversas circunstancias y con un material asimismo recuperado con carácter 
de urgencia, en el que se había dado prioridad a los hallazgos antropológicos por los interesantes descubrimientos registrados. Estos hechos perjudicaron considerablemente la obtención metódica de las coordenadas del material para su posterior estudio de laboratorio e interpretación.

La excavación aportó una gran cantidad de material cerámico de procedencias y cronología diversas. Conocer el proceso técnico utilizado en la fabricación de cada uno de estos tipos cerámicos fue, entre otros, lo que permitió identificar los rasgos que definían a cada serie concreta. Por eso hemos decidido dar a conocer los resultados de cada una de ellas, de manera individual. La que presentamos a continuación corresponde a la serie que se conoce como "cuerda seca".

\section{DATOS HISTÓRICOS EN TORNO AL YACIMIENTO}

La fecha exacta del establecimiento de San Francisco de Asis de las Palmas de G.C. no se ha podido determinar con precisión. Algunos autores creen que se realizó antes de terminar la Conquista en unos terrenos que fueron cedidos a los franciscanos por Juan Rejón ${ }^{2}$, trayéndolos a las islas con el propósito de encargarles la conversión de los canarios. Una segunda versión retrasa la fecha de tal acontecimiento a los años posteriores a la Conquista. Para ellos fue Pedro de Vera -sustituto de Juan Rejón- el que les señaló el sitio al norte de la incipiente villa para que levantaran el cenobio, después de la concesión por los Reyes Católicos de la prerrogativa de fundar conventos y monasterios en el Reino de Granada y en las Islas Canarias, a partir de la bula Dum ad illam otorgada por el Papa Inocencio VIII el 14 de septiembre de 1486 (Millares, 1860, tomo I:357) (Morales, 1978:253) (Marín y Cubas 1986:219).

Aunque haya disparidad de opiniones sobre quién entregó los terrenos, si Rejón o Vera, o si tal acontecimiento fue anterior o posterior a la conquista definitiva, sí conocemos, en cambio, las delicias de su ubicación, de sus verdes y frondosas huertas favorecidas por una acequia que partía del barranco Guiniguada y llegaba hasta Triana (Paetow, 1992:53),

1 Los datos históricos del yacimientos aparecen publicados también en el trabajo sobre loza dorada editado en el Butlletí Informatiu de Ceràmica, $n^{o}$ 82-83 juliol-desembre 2004. Considero oportuno repetirlo al tratarse de trabajos divulgados en provincias diferentes, por lo que se hace necesario contextualizar cada una de las series para una mayor comprensión del lector.

2 Jefe de la expedición castellana enviada en 1478 por los cuyo caudal había sido concedido por cédula real de los Reyes Católicos.

De este modo, aunque no disponemos de la suficiente información para precisar cuándo se "colocó la primera piedra", sin embargo, podemos utilizar, gracias a la documentación existente, los siguientes márgenes cronológicos: entre 1480, año de la llegada de Vera a Gran Canaria, y 1486, año de la concesión de la citada bula papal.

Unos años más tarde, en la relación que Guillermo Coma realiza sobre el segundo viaje de Colón a las islas Canarias (1493-1496) cita específicamente el convento franciscano de Las Palmas:

“Después arribaron a Gran Canaria.... En las Canarias se han establecido colonias bajo los auspicios de los Reyes de España, y se ha provisto con diligencia cuanto conduce a dar lustre a una provincia: hay alli un obispo hospitalario, se acude a un templo venerable, un monasterio de franciscanos observantes, que han construido un edificio que tiene pujos de belleza; hay, además, mercaderes de mil lugares, artesanos expertos en casi todos los oficios, población numerosa" ${ }^{3}$.

A finales del siglo XVI, todo parece indicar que la fisonomía del convento estaba ya consolidada. Unas líneas maestras que debieron mantenerse a lo largo del tiempo, consistentes en un edificio de dos plantas a las que se accedía por corredores abiertos, cuyas dependencias se distribuían en torno a dos patios, formado por dos claustros, entre los que se distribuían las celdas, el refectorio, la enfermería, la cocina, graneros, bodega y hasta una hospedería (Alzola, 1986:20). (Figura 1)

Desgraciadamente, cuando con seguridad aún no se habían concluido las labores de carpintería, el convento de San Francisco se vio amenazado por las llamas, debido al ataque del holandés van der Doez a Las Palmas en 1599. Gracias a que fue el último edificio al que se le prendió fuego, el incendio pudo ser sofocado por los frailes y los vecinos que rápidamente acudieron en su ayuda. Sin embargo, la devastadora incursión supuso la destrucción completa de la incipiente iglesia se San Francisco y parte del ala del claustro contigua al templo ${ }^{4}$.

Reyes Católicos para la Conquista de Gran Canaria.

3 Texto 55. El Segundo Viaje de Colón a Gran Canaria y La Gomera. Descripción de las Islas Canarias. Relación de Guillermo Coma. Fuente: Relación de Guillermo Coma, Traducida por Nicolás Esquilache. En J. Gil y C. Varela. Ed. Cartas de particulares a Colón y Relaciones coetáneas, 1984: 183, 184, 185. (Tejera, 2002).

4 Memoria de la excavación, p. 6. 


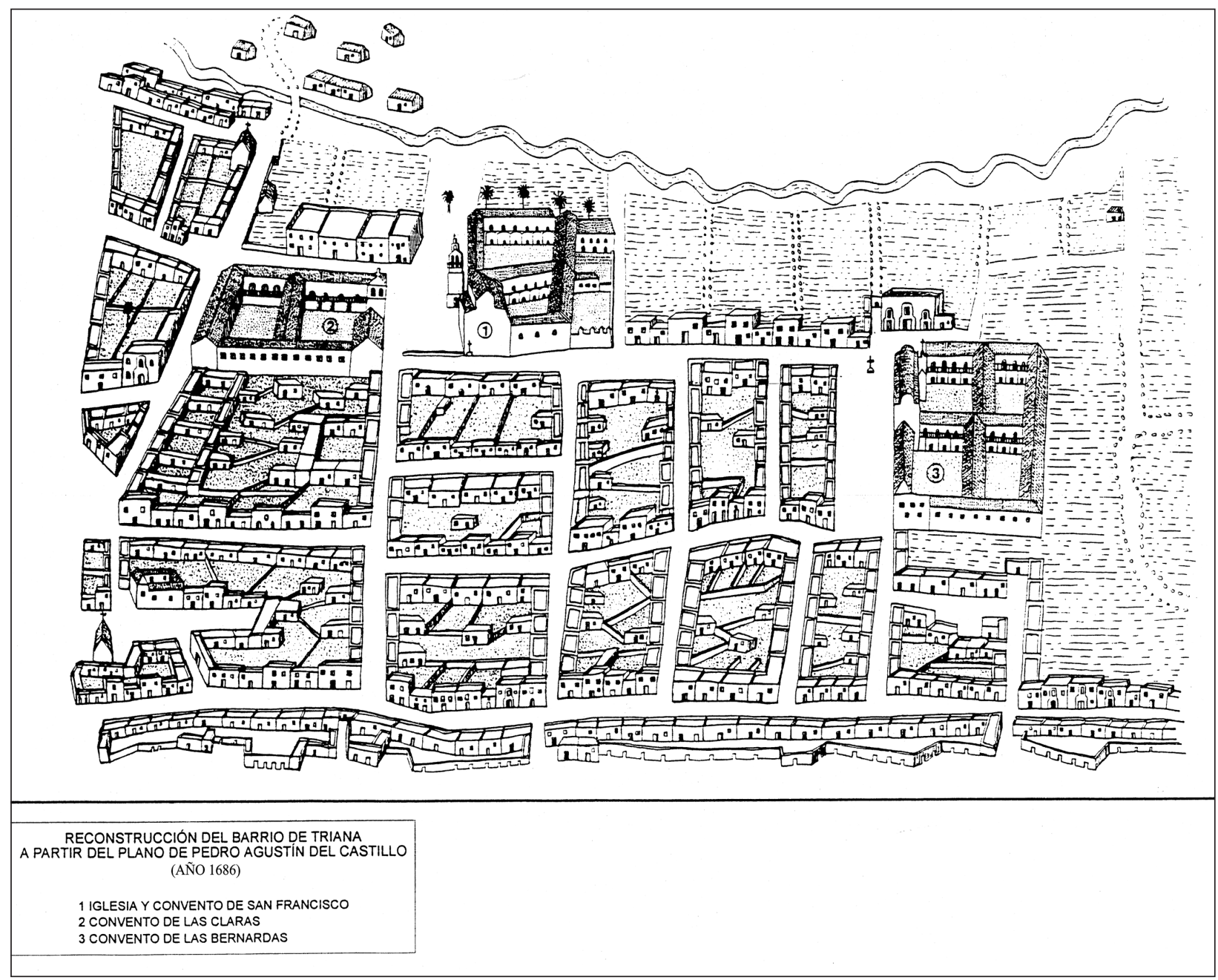

Figura 1. Reconstrucción del barrio de Triana a partir del plano de Pedro Agustín del Castillo (1686).

Después de este suceso, está registrado cómo las obras de reconstrucción comenzaron por la residencia, al ser prioritarias para el desarrollo de la vida diaria. El documento es una carta fechada en 29 de febrero de 1600 , suscrita por el maestro de cantería Luis Morales, según el cual obligaba a desbastar

"toda la cantería que fuere necesaria para tres arcos y dos pilares que faltan en el claustro del convento de señor San Francisco de esta cibdad y asentallos después de avellos labrados en la forma y de las mesma lavor y obra que estan los demás arcos del dicho claustro..." (Lobo, 1981, doc. 53) (Alzola, 1986:3).

Otra de las estructuras que formaban parte de la fisonomía del convento de San Francisco era el muro que lo rodeaba, y que era el límite con el de

5 Queremos dejar constancia de este dato porque cuando se procedió al alumbrado en el año 1992 de la actual plazoleta de Colón, delante de la Iglesia de San Francisco de Asís, se
San Bernardino de Sena, de la orden de Santa Clara. En este caso, de lo que tenemos noticia es de su demolición en el año 1664.

En 1737 se abre un procedimiento legal sobre este hecho, cuando un fraile testifica que, desde su fundación, el convento había estado rodeado de una muralla por la parte de la plazoleta hasta donde llegan hoy los álamos, con sus puertas de cantería y que por falta de dinero se había ido cayendo. Corrobora este apunte el testimonio de un individuo de 82 años quién asegura haber visto dicho muro y que en una de las esquinas "estaba el osario" (Cuenca et al, 1993:34-35).

Parece que en el siglo XVIII no se hicieron muchas obras, a no ser las obligadas para rehabilitar el cenobio después de las inundaciones que sufrió,

hallaron unos restos óseos humanos que quizás correspondan al osario al que se refiere el testigo. 
debido al desbordamiento del barranco Guiniguada en los días 26 y 27 de enero de 1713 .

"La tempestad se rueda sobre Gran Canaria. El barranco de Guiniguada se lleva el Puente de Las Palmas; derriba el Convento de S. Francisco, destruye campos y sembrados y las lluvias hacen perecer mucha gente" (Millares, 1700-1749, tomo V: 59).

Quizás como consecuencia de este suceso se rellenaron los sótanos del edificio, como se deduce de los resultados arqueológicos.

$\mathrm{Si}$ conocemos el aspecto externo del inmueble gracias a las descripciones históricas conservadas, su evolución y la distribución interna es algo más confusa. Aunque sabemos, a grandes rasgos, sobre la ubicación de sus huertas y la existencia de dos claustros, queda aún por esclarecer, sin embargo, cuál era la zona del cenobio dedicada a cementerio antes del Decreto de 1802.

Es cierto que existe documentación al respecto sobre determinados personajes enterrados en el convento, en la capilla de los Terceros o en el altar mayor de la iglesia; pero a excepción de dos de ellos, que se especifica están enterrados en la Portería, pocos son los datos de ubicación exacta de los sepelios dentro del recinto monacal. Las únicas referencias conservadas sobre las inhumaciones fueron las realizadas entre los años 1796 y 1806.

Después de trescientos años de vida, los franciscanos se vieron obligados a abandonar el convento como consecuencia de la Desamortización decretada por el Gobierno en 1835. Como resultado, el cenobio pasa a manos del Estado. Y desde 1849 comienza a utilizarse como cuartel de Artillería, para pasar luego al cuerpo de Ingeniería, y en 1893 al de Infantería.

Aunque hasta la fecha en que fue ocupada por los militares la residencia apenas sufrió grandes reformas, una vez ocupada, rehabilitaron todo el conjunto para adaptarlo a las nuevas necesidades (Cuenca et al, 1993:35). Y entre los cambios producidos conocemos el que publica el periódico $\mathrm{El}$ Ómnibus de 1856, notificando la desaparición de la antigua Portería que había sido sustituida por una nueva fachada ${ }^{6}$.

A pesar de la lamentable falta de documentos, contamos con algunos, aunque fragmentarios e incompletos, que nos proporcionan una idea de la importancia y magnitud del cenobio en sus inicios. Algunas noticias que hacen referencia a su descrip- ción, a su vida y sus avatares, e incluso dibujos insertos en planos de la ciudad, nos permiten conocer asimismo algunas de las remodelaciones realizadas a lo largo de su historia, ayudándonos en gran medida a reconstruir la dinámica del edifico en sus casi cinco siglos de existencia.

\section{LA CERÁMICA DE CUERDA SECA}

Cuando empezamos a estudiar la técnica sobre el proceso de elaboración empleado por los alfareros para la confección de la cuerda seca nos encontramos con distintas versiones. Por este motivo decidimos recoger en un primer apartado las diversas opiniones registradas entre los distintos investigadores que han analizado esta serie cerámica a lo largo de los años.

Sin embargo, nuestro objetivo será conocer cuál fue el centro de producción original de los fragmentos recuperados en la excavación grancanaria y en qué fechas llegaron a nuestras costas. La escasez de documentación que existía sobre este tipo de cerámicas en el ámbito canario nos llevó a indagar sobre su origen más remoto. Por eso, dedicamos otro apartado a la enumeración de los centros históricos de producción, -conocidos gracias a las intervenciones arqueológicas-, desde el Próximo Oriente hasta la Península Ibérica. Esta recapitulación nos permitirá acercarnos a los lugares en los que se han documentado talleres, hornos o testares con desechos de alfar, testigos, entre otros, de producciones alfareras. Estos datos, junto a los análisis morfológicos de los recipientes cerámicos recuperados, unidos a los testimonios históricos y cronológicos de cada yacimiento, nos permitirán, a la vez, catalogar los fragmentos recuperados en la excavación franciscana mediante la comparación con los restos arqueológicos obtenidos en aquellas intervenciones bien contextualizadas.

En el recorrido sobre los estudios precedentes hemos dividido el trabajo en dos partes, porque la serie sobre la que se desarrolla la técnica de cuerda seca se aplicó sobre piezas con dos funcionalidades diferentes: por un lado las piezas de vajilla y, por otro, los azulejos, destinados a la ornamentación arquitectónica.

En las últimas páginas presentamos la caracterización de los fragmentos de cuerda seca registrados en el convento de San Francisco de Asís de Las Palmas de Gran Canaria. A la descripción decorativa y tipológica le acompañan las ilustraciones correspondientes, tan necesarias para los arqueólogos, con el fin de que puedan ser reconocidas y uti-

6 El Ómnibus n n 144, Las Palmas, 17 de diciembre de 1856. 
lizadas por otros investigadores.

Exponemos, asimismo, los criterios utilizados en nuestro proceso deductivo, explicando porqué llegamos a la conclusión de que los vestigios exhumados corresponden a piezas sevillanas fechadas entre de finales del siglo XV o la primera mitad del XVI.

\section{PROCESO DE ELABORACIÓN}

En el siglo XIX un ceramólogo, el barón Davillier, repara en una cerámica española cuya técnica decorativa describe como "un curioso ejemplar que tiene la apariencia de "sgrafiato" o loza grabada de Italia, pero hecho en realidad por otro procedimiento, sin el empleo del engobe de tierra blan$c a$ " 7 .

En 1904 Gestoso y Pérez, a partir de un documento del Archivo de la Catedral de Sevilla en el que aparece el vocablo cuerda seca, propone que dicho término alude a la técnica decorativa en cuestión, y que es una expresión que se refiere a las líneas de manganeso utilizadas para separar los vedríos de colores sobre el barro juagueteado.

A pesar de que este escrito no es aceptado por la mayoría de los autores por ser una denominación dudosa, lo cierto es que, desde entonces, se utiliza para describir esta decoración.

Es, asimismo, Gestoso (1904:113) el primero que narra la elaboración de esta técnica. Para este autor "Las figuras fueron dibujadas sobre el juaguete, con tinta de manganeso y una sustancia grasienta, con una brocha dejan caer en lo espacios limitados por los perfiles negros los acuosos esmaltes o vedríos, que una vez depositados sobre el barro se secan rápidamente al absorber el agua".

Tres décadas más tarde, González Martí (1933:52) al hacer referencia al proceso de elaboración de la técnica, añade la necesidad de un estarcido sobre el barro bizcochado. “...se repasan sus contornos con aceite (en la actualidad de linaza) que llevaba disuelto un color cualquiera. Preparados en varios recipientes diferentes óxidos mezclados con cubierta (vidriado plumbífero compuesto por 10 partes de óxido de plomo, otras 10 de sílice o arena y 3 de sal) de ellos se iban tomando porciones para rellenar los huecos del dibujo. Sometida a una segunda cochura quedan vitrificados los óxidos y la cubierta perfectamente contor-

7 Las cerámicas a las que se refería son las conocidas como lote Zavellá. Recuperadas en Palma de Mallorca en 1937, se conservan hoy en el Museo de Cerámica de Barcelona. Realizadas en cuerda seca parcial, su técnica de elaboración está asociada al esgrafiado (Martínez, 1991:67). neada, porque la raya o cuerda grasa del dibujo negro, mate, seco, detiene y delimita la mezcla vítrea, que queda como en altorrelieve sobre el bizcocho".

Estudios posteriores de autores como Almagro Basch y Llubiá Munné (1962:12-14) describen la aplicación del dibujo mediante el trazado de óxido de manganeso impuro sin fundente .

Apenas unos años más tarde, Ceballos Escalera (1966:23), refiere el trazado del dibujo a partir del sulfuro de manganeso.

En el II Coloquio de Cerámica Medieval del Mediterráneo Occidental, celebrado en Toledo en 1981, Carmen Aréchaga (1986:409-413) presenta un trabajo sobre los antecedentes de la loza de cuerda seca en Toledo en el siglo XV. Para ella la línea consistía en "óxido de manganeso, mezclado en ocasiones con silicato de plomo, al que se le añade una grasa orgánica”. Indicaba, además, los componentes de los vedríos cuya fórmula aproximada sería: "minio o litargirio, en un $60 \%$ cuarzo en un $20 \%$ y caolín en un $10 \%$. Vedríos coloreados a base de óxidos metálicos formando una paleta reducida de óxidos ${ }^{8}$ de manganeso, de hierro, cobre, estaño o cobalto, en un 6 y un $8 \%$ aproximadamente, diluidos en agua y aplicados con pincel o espátula sobre el barro, rellanando las zonas separadas por la "cuerda seca".

Con todas estas definiciones recopiladas a lo largo de ochenta años de investigación, no es extraño, ante la diversidad de disquisiciones sobre el proceso de elaboración de la cuerda seca, que en el antedicho Coloquio de Cerámica Medieval, José Aguado Villalba (1986:132) formule varias preguntas sobre cómo se obtiene la línea negra de la cuerda seca: ¿Con manganeso y grasa? ¿Con manganeso muy impuro? ¿Sólo con grasa? ¿Con sulfuro de manganeso disuelto en aceite?" Junto a estos interrogantes se plantea una segunda cuestión: ¿Cuántas cocciones eran necesarias una sola o dos?

En su comunicación intenta demostrar, por un lado, que la producción de cuerda seca existió en Toledo, hasta ese momento en entredicho; y por otro, aporta algunas novedades sobre el proceso de elaboración. Para él consistía en lo siguiente: "tostado a $900^{\circ} \mathrm{C}$ el manganesos natural, machacado y molido era disuelto en agua y aplicado a pincel

8 La gama que nos ofrece es: el negro del óxido de manganeso; el melado del óxido de hierro; el verde del óxido de cobre; el blanco al añadir estaño y el azul del óxido de cobalto (Aréchaga, 1986:409-413). 
sobre la pieza cruda, pero no seca totalmente, sino verde u oreada" añade que para las separación de los colores "algunas veces en vez de manganeso se usó almagra” porque en algunas piezas las líneas separadoras de los esmaltes son rojizas. Este autor afirmó, además, que para la realización de la pieza sólo era necesario una cochura. Lo comprobó a partir de algunos fragmentos descubiertos en Toledo, aún crudos, pero decorados. Estas circunstancias son las que explicarían el porqué de las líneas poco precisas de la cuerda seca islámica.

Pero a pesar de lo acertado de sus conclusiones, hemos de tener en cuenta que Aguado estudia el caso concreto de la cerámica toledana, y que éstas se elaboraron en un contexto que cubren un marco cronológico que abarcaría los siglos XI y XII; por tanto, no podemos generalizar este proceso para el resto de los alfares que produjeron la cerámica de cuerda seca en la Península, y mucho menos prolongarlo en el tiempo, mientras los resultados arqueológicos no demuestren lo contrario.

Probablemente, como el manganeso disuelto sólo en agua no era capaz de aislar totalmente los colores para que no se mezclaran; esta situación daría lugar, en el caso de las cerámicas bizcochadas, a la adición de algún fundente, es decir, cualquier silicato, para que la cuerda fuera capaz de separar los colores.

En la década de los noventa, Balbina Martínez Caviró (1991:45), recoge la definición de Aguado para las cerámicas de Toledo, pero vuelve a insistir en la aplicación del estarcido, como señalara en su momento González Martí, en la utilización de la sustancia grasa mezclada con manganeso y en la vitrificación de los esmaltes tras una segunda cocción, como definición general en el proceso de elaboración de cuerda seca.

Sin embargo, creemos que la definición común de cuerda seca-manganeso mezclado con grasa y dos cochuras- no siempre es válida, al menos para los inicios de la producción. Esta enunciación es más correcta para el segundo período de esplendor de la fabricación de la cuerda seca en la época de los Reyes Católicos, como tendremos ocasión de ver.

Pero esta técnica no se empleó sólo en piezas de vajilla, sino también en los azulejos. Alfonso Pleguezuelo (1989:29-33) realizó un estudio detallado de los ejemplares de la colección del Museo de Artes y Costumbres Populares de Sevilla9, con lo

9 M.A.C. P. S. a partir de ahora.

10 En estos momentos estamos estudiando los azulejos de arista recuperados en el solar del antiguo Convento de San que consiguió distinguir tres modalidades. En primer lugar, lo que denomina "cuerda seca hendida", en donde la separación de los esmaltes se asegura con la realización de un surco rajado sobre el barro fresco, antes de la ejecución del dibujo y de la aplicación de los óxidos. En segundo lugar, la llamada "cuerda seca plana", en la que el dibujo se efectúa directamente sobre la superficie lisa de la pieza. En tercer lugar, la conocida como "cuerda seca de refuerzo", combinando la técnica de cuerda seca con la usada en los "azulejos de arista" ${ }^{10}$, para subrayar la separación de los esmaltes de colores; quizás sea incluso una práctica de tránsito entre ambas modalidades.

En resumen, la definición correcta del proceso de elaboración de la técnica de cuerda seca para los ejemplares recuperados en el solar del antiguo convento de San Francisco de Asis de las Palmas de G.C.,-por pertenecer cronológicamente al segundo período de apogeo de la técnica-, sería que ésta se consiguiese al imprimir las líneas básicas del diseño que se quiere representar, sobre la superficie del barro, mediante un estarcido o por medio de una matriz de metal o madera, en el caso de los azulejos. A continuación se repasan las líneas del dibujo con óxido de manganeso mezclado con una sustancia grasa. El fin de esta mezcla es evitar la unión de los colores. Los distintos esmaltes se irán aplicando con pincel o espátula rellenando los espacios libres entre las zonas que hemos delimitado con la "cuerda seca". El resultado final, cocida la pieza por segunda vez, son los esmaltes vitrificados en relieve con respecto a las líneas calcinadas de manganeso.

\section{CENTROS HISTÓRICOS DE PRODUCCIÓN DE CUERDA SECA}

$\mathrm{Al}$ analizar los yacimientos en los que se han recuperado fragmentos o piezas de cuerda seca, uno de los fines es establecer una seriación entre los distintos lugares de producción para demostrar si hubo o no continuidad en su elaboración desde las primeras Taifas hasta la Baja Edad Media. El segundo objetivo se centra en conocer el posible traslado de alfareros, como consecuencia del exterminio de algunas ciudades, derivado de acontecimientos políticos o de otra índole. Por último, hacer una tipología que ayude a clasificar las piezas recuperadas en otros contextos arqueológicos.

Por este motivo se decide agrupar los hallazgos

Francisco de Las Palmas. Será publicado en un próximo trabajo. 
atendiendo a las etapas históricas conocidas, sabiendo que no coinciden exactamente con las fases políticas a las que hacen referencia los términos utilizados. Las fechas de las piezas reseñadas corresponden a las que los investigadores les han adjudicado. Hemos de tener en cuenta que cada ciudad a la que se asocia el hallazgo tuvo una vida y evolución propias, máxime si nos referimos al período de las primeras Taifas. Debemos considerar, además, que aún quedan muchas ciudades por estudiar con método arqueológico y que, probablemente, aún están ocultos los restos que demuestran la producción alfarera en muchas de ellas. Por otro lado, algunos de estos yacimientos se estudiaron siguiendo la metodología vigente en la década de los 80 , por lo que la adscripción de sus piezas a un período cronológico se hace difícil, porque en algunos casos las primeras campañas fijaron su interés en la sistematización de los restos arquitectónicos. De este modo, desde el punto de vista arqueológico, no ofrece una secuencia estratigráfica que ayude a datar las piezas cerámicas, a las que por otro lado no se les prestó demasiada atención. Otras cerámicas, las más espectaculares, fueron adquiridas por coleccionistas en el siglo XIX, por lo que muchas de ellas no están contextualizadas.

\section{Producción del Próximo Oriente}

Durante mucho tiempo se pensó que la técnica de cuerda seca era un invento de los musulmanes hispanos, y que se había producido por primera vez en al-Andalus. Por el contrario, se ha demostrado que se fabricaba en Mesopotamia antes de la producción española ${ }^{11}$ (Soler, 1988:64-65). Otros autores han señalado que esta fábrica ya existía, incluso, desde el Egipto faraónico (Martínez, 1991:45) por lo que esta cerámica -al igual que la loza dorada ${ }^{12}$ se puede vincular a un origen próximo-oriental, floreciendo -a través de la costa tunecina (Lister \& Lister, 1987:47)- desde Persia hasta la Península Ibérica en los siglos siguientes (Ainaud, 1952:233).

\section{Producción en la Península ibérica ÉPoca CALIFal}

Las fechas más antiguas de cuerda seca andalu-

11 La pieza omeya más antigua decorada con la técnica de cuerda seca parcial es una jarra hallada en Susa, al modo de numerosas piezas andalusíes de fecha posterior (Martínez, 1991:18).

12 Ver Sosa, 2004:21-41.

13 Este yacimiento aporta una cronología de producción precisa, pues la ocupación del arrabal abarcó desde el año 1022 sí corresponden a los yacimientos de Elvira (Granada) y Medina Azahara (Córdoba), dos ciudades que se extinguen en 1010, (Martínez, 1991:46). No sabemos si sus cerámicas fueron producciones locales o fruto de relaciones comerciales con Oriente. Otras excavaciones más recientes realizadas en Cádiz han sacado a la luz algunos fragmentos de cuerda seca parcial, en el interior de un pozo del Alcázar pre-almohade en Jerez de la Frontera, cuyos paralelos formales han sido catalogados entre los siglos X y XI (Aguilar et al, 1998:163-173); sin embargo, como en los casos anteriores se desconoce, por el momento, la existencia de alfares que produjeran estas labores en fechas tan tempranas.

El problema es deducir cuál sería el lugar de producción del período califal. Ceballos Escalera (1966:33-34) apunta como alfar original la ciudad de Almería. Quedó bien demostrado tras las excavaciones de la Alcazaba, en donde se descubrieron los hornos que producían cuerda seca. No es extraño, puesto que Almería fue el centro principal de comunicación con Oriente en época califal. Probablemente desde aquí se derivaría la producción a otros centros como Málaga y Granada.

También se ha barajado la posibilidad de una producción en el Norte de África, en Marrucecos. Así lo sugieren especialistas en cerámica que han localizado algunas piezas en estas fechas, en iglesias italianas (Berti et al, 1993:15-19).

\section{Primeras taifas y periodo ALMORÁVIDE}

Para los siglos siguientes, XI y XII, el yacimiento más importante, sin duda, es la Alcazaba de Badajoz. Las excavaciones realizadas entre 1977 y 1981 sacaron a la luz, no sólo un completo lote de cerámicas de cuerda seca, sino que contribuyó al descubrimiento casual de un testar taifa al otro lado de la ciudad extremeña. Con este hallazgo se documentaba arqueológicamente la existencia de un alfar del siglo $\mathrm{XI}^{13}$, ya descrito por al-Idrisi (Martínez, 1991:52), lo que acentúa la fiabilidad de las referencias del viajero.

Las ciudades que elaboraron cuerda seca en estas fechas, en el territorio de al-Andalus fueron, Málaga $^{14}$, a juzgar por los análisis mineralógicos

hasta principios del año 1095 aproximadamente, sabiendo -con seguridad- que en 1113 el arrabal se había destruido (Casamar Y Valdés, 1984:396-398).

14 Los hallazgos corresponden a la Alcazaba, bajo la Torre del Homenaje. Diecisiete piezas fechadas entre el siglo XI y principios del XII (Casamar y Valdés, 1984:390-391). (Almagro-Basch y Llubià, 1952: XIV). 
realizados, y Almería ${ }^{15}$. Otras localidades que pudieron elaborar cuerda seca, a juzgar por los hallazgos, son Cádiz ${ }^{16}$ y Sevilla ${ }^{17}$.

Otras manifestaciones de cerámica de cuerda seca parcial y total, dentro del territorio peninsular pertenecen a Murcia ${ }^{18}$ (Martínez, 1991:59) y a Valencia (Soler, 1988:62-65).

Avanzando hacia el Norte, por el Mediterráneo, otro de los territorios a analizar, por ser de gran tradición alfarera, es la actual zona catalana. Sin embargo, por el momento, sólo conocemos la existencia de hallazgos puntuales en Tarragona, así como un grupo de vasijas rescatadas en el Castillo de Balaguer en Lérida (Martínez, 1991:53) (Casamar y Valdés, 1984:388). Estas cerámicas coinciden con los dos períodos de esplendor de la fortaleza: el taifa -siglo XI- en el que se consignan fragmentos de cuerda seca parcial, y el bajomedieval -siglos XIV y XV-.

Por lo que se refiere al área de actual Castilla-La Mancha, así como los posibles centros de producción asociados a esta zona, ha sido de gran interés el descubrimiento del testar del Puente de San Martín, y el análisis de sus fragmentos llevados a cabo por Aguado Villalba (1983). A este acontecimiento hay que unir el descubrimiento de un horno cerámico islámico en el circo romano de Toledo, permitiendo fechar todo el conjunto toledano en el siglo XI. Lo que aún no se ha localizado es el alfar adscrito al testar intramuros. En palabras de Balbina Martínez Caviró, (1991:41) “después de la incorporación de Toledo al reino Leonés, los alfares estuvieron situados extramuros en San Ildefonso, en el arrabal llamado después de La Antequeruela. Estos datos permiten otorgarle al testar un momento indetermina-

15 Los ejemplares se localizaron en Pechina (Almería) y en la ciudad de Almería, con una cronología comprendida entre los siglos XI y XII, aunque algunos fragmentos han llegado a fecharse en el siglo XIV. (Casamar y Valdés, 1984:390).

16 En el caso de Cádiz contamos con una jarrita, elaborada con la misma técnica parcial recuperada en el yacimiento de Los Caños de Meca y fechada en los siglos XI y XII (Abellán et al, 1981:141-147).

17 En la ciudad de Sevilla, para estas fechas, la única pieza con la que contamos, por el momento, es un brocal de pozo elaborado con cuerda seca parcial fechado en el año 1038 y conservado en el Museo Arqueológico Nacional (Martínez, 1991:56). Además se encontró un desecho de horno datado en los siglos X-XII (Casamar y Valdés, 1984:391).

18 Incluimos una jarra elaborada entre los siglos XI y XII (Llubià, 1973:60). Algunos hallazgos procedentes de la ciudad de Murcia catalogados en época taifa (Casamar Y Valdés, 1984:390). Otros yacimientos murcianos son el do del siglo XI y segunda mitad del XII”.

El propio Aguado (1983:16) recoge una afirmación de J. Zozaya, quien propone otra posible área de producción en Alcalá de Henares desde finales del califato. Lo único que conocemos es el alto grado de dispersión por yacimientos castellanos de fragmentos cerámicos, pero sin la presencia de restos de utillaje de taller que prueben su manufactura (Aguado, 1983:69). De todos modos, no descartamos su existencia ${ }^{19}$.

Por tanto, los centros de producción seguros, a falta de excavaciones arqueológicas, pertenecen a Almería, Badajoz y Toledo; algunos alfares taifas que producían loza de cuerda seca se localizarían, entre otros, en Sevilla, Málaga, Valencia y Murcia. Debió existir algún centro aragonés, catalán e incluso en alguna otra ciudad castellana, pero lo cierto es que no encontramos yacimientos que justifiquen $y$ demuestren esta afirmación, pues la mayor parte de las excavaciones se han centrado en los restos romanos, relegando a un segundo plano los hallazgos islámicos superpuestos en la mayoría de las ciudades peninsulares.

Aunque probablemente la mayor parte de las cerámicas taifas son fruto de producciones de alfares locales, muchas de estas creaciones peninsulares fueron exportadas dentro y fuera de nuestras fronteras desde época temprana, como lo demuestran, entre otros, los hallazgos en las islas Baleares. Algunas piezas fechadas entre los siglos XI y XIII han sido recuperadas en Mallorca (Martínez, 1991:52-67) y en Ibiza (Gómez, 1926:26). Siguiendo la ruta comercial hacia el Este están documentados algunos ejemplares en el Norte de

Convento de las Madres Agustinas, las viviendas de San Antolín, la calle de San Antonio y la calle de San Nicolás, la Plaza de Santa Eulalia, en el casco urbano, así como el Cementerio de San Nicolás y el Cerro del Castillo (Navarro, 1986).

${ }^{19}$ Descubrimientos vinculados al siglo XI y que podrían estar relacionados con el alfar toledano son las vasijas recuperadas en yacimientos como Vascos (Navalmoralejo) y Olmos, un trozo en la Plaza del Pan en Talavera de la Reina y en el mismo Toledo (Casamar y Valdés, 1984:391). Otros vestigios madrileños se localizan en Calatalifa, Ribas y Valderrodela, así como algunos restos y piezas completas como el plato de cuerda seca parcial hallado en Alcalá la Vieja en Madrid, conservado en el Museo Arqueológico Nacional. Por último, incluimos los fragmentos encontrados en Paracuellos y Jadraque (Guadalajara) (Martínez, 1991:52). 
África ${ }^{20}$. La difusión por el Norte del Mediterráneo se constata también gracias a la presencia de estos objetos en puntos de la geografía italiana. Se han localizado fragmentos de cuerda seca en las iglesias de San Piero a Grado y San Sixto, en Pisa, Italia, cuyos investigadores asocian a manufacturas procedentes de España-Marruecos atribuidas a los siglos X y XI, paralelos a la fabricación de Medina Azahara (Berti et al, 1993:15-19) (Villarroel, 2002:46).

\section{Período almohade}

En este periodo incluimos los hallazgos fechados entre los siglos XII y XIII.

Entre los lugares de elaboración de la actual Andalucía $^{21}$ hemos de destacar Almería ${ }^{22}$ y Málaga ${ }^{23}$, pues gracias a análisis de laboratorio realizados sobre algunos restos de cuerda seca parcial, encontrados en la Alcazaba de Málaga, confirman un origen tanto almeriense como malagueño. Para los fragmentos de cuerda seca total, no hay certeza de esta procedencia, pues podría ser cualquiera de las dos localidades (Martínez, 1991:56). Lo más importante, en ambos casos, es que ya existía en estas fechas una producción peninsular y que, por tanto, no se trata de objetos importados. Una fabricación que continúa en el período nazarí, como lo demuestran los hallazgos de la Alcazaba de Málaga (Martínez, 1991:75).

Algunas publicaciones específicas del área murciana incluyen los fragmentos de cuerda seca recu-

20 Hallazgos por el Norte de África se han localizado en Dsira fechado en 1152 (Lister \& Lister, 1987:115), otros ejemplos se han localizado en Marruecos (Belyounech, Alcácer Seguer, Salé, Marraquesh), Argelia (Tremecén, Bugía, Qal'a de los Banu Hammad), Egipto (Fustat), Turquía (Antioquia del Orontes). Aunque estos hallazgos también pueden ser fruto de producciones locales en al-Magrib alAqsà, desde al menos el siglo XII, o quizás desde el siglo anterior, es probable que algunos ejemplares, como los de Fustat, pudieron ser objetos de procedencia peninsular fruto del comercio mantenido en el siglo XI (Casamar y Valdés, 1984:390-395).

21 Los hallazgos en la actual Andalucía corresponden a Cádiz, entre otros los yacimientos de Mesas de Asta (Esteve, 1960) y los fragmentos de cuerda seca parcial y total recuperados en La Encarnación, en el casco urbano de Jerez de la Frontera (Fernández, 1987). En Asta Regia se realizaron excavaciones en 1942, 1943 y 1986. Por los datos recuperados parece que la ciudad fue abandonada con la Reconquista, por lo que el material pertenece a los siglos XII y XIII. Como en los casos anteriores la falta de estudios estratigráficos impide la fijación de una cronología más concreta, así como la posibilidad de conocer si estas localidades produjeron estas labores (Casamar y Valdés, 1984:395) (Martínez, 1991:54-55).

22 Hablando de la técnica, Martín Almagro dice "Ésta se nos perados entre los siglos XIII al XIV (Casamar, 1984:390). Gracias a las excavaciones realizadas en Murcia en los años 80 en el cementerio de San Nicolás, ha podido constatarse la existencia de un horno y testar en la ciudad levantina, correspondiente a manufacturas cerámicas de los siglos XII Y XIII (Navarro, 1986). Sin embargo, desconocemos, por el momento, si el alfar estaba especializado en la elaboración de cuerda seca o los hallazgos catalogados son fruto de las relaciones comerciales con ciudades taifas cercanas.

Hubo otras áreas como la valenciana ${ }^{24}$ que elaboraron cuerda seca parcial, cuyas piezas -fechadas en los siglos XII y XIII- se caracterizaron por no llevar barniz blanco de estaño, a pesar de que las anteriores, las del siglo XI, sí lo llevaban. Si en tiempos del Califato y reinos de Taifa el estaño procedía del Norte de África, en época cristiana pasó a ser Inglaterra, el lugar de abastecimiento. Este dato -en palabras de $\mathbf{M}^{\mathrm{a}}$ Paz Soler Ferrer (1989:64-65)podría estar asociado a un cambio de proveedor del estaño como consecuencia de la ruptura de las relaciones comerciales, lo que provocaría la escasez del producto durante un tiempo. La autora apunta la posibilidad de que estos hechos afectaran más concretamente al territorio valenciano, reflejado en la dificultad de obtener estaño. Podemos decir, en términos generales, que los yacimientos islámicos de Valencia cuentan con un voluminoso fondo de cerámicas comunes y decoradas entre las que se encuentran las de cuerda seca parcial y total $^{25}$.

En Paterna, la referencia más antigua es del siglo

ofrece ya en los talleres de Almería, siglo X, o quizás antes, y luego en la cerámica de Málaga, derivadas de aquella..." (Aguado, 1983:16)

23 Una jarra de cuerda seca parcial y un fragmento con decoración figurada, así como parte de una orza decorada con animales, procedentes de este contexto se conservan en el Museo Arqueológico de Málaga y están fechadas en los siglos XII y XIII (Martínez, 1991:55-56. Fig. 29-31).

24 La gran difusión de la cuerda seca queda patente en los hallazgos de Benicarló, Villavieja y Jérica (Castellón); en el castillo de Castalla (Alicante); (Casamar y Valdés, 1984:389-390).

25 Entre otros podemos citar el hallazgo de la calle Calabazas en la ciudad valenciana (Ribera y Lerma, 1984:37-44), así como los hallazgos de Olocau, Liria, Játiva, Corbera, en el aljibe del Palacio de Martín el Humano, en Paterna y Sagunto (Valencia), cuyos fragmentos aparecieron gran parte en la excavación de la plaza de la Almenara y otros en la de Armas y que se han fechado entre los siglos XII y XIV. Otros fragmentos de cuerda seca se recuperaron en la misma ciudad valenciana. En este caso, la mayoría de las piezas se recogieron durante las obras del Mercado Central, algunos en el cauce del río Turia y otros proceden de los niveles árabes de la plaza de la Almoyna. Todos ellos, en cualquier caso fechados entre los siglos XII y XIV (Casamar y Valdés, 1984:389-390). 
XII y está relacionada con la cuerda seca parcial. No se sabe, en cambio, con precisión la fecha de su desaparición (Villarroel, 2002:52).

Cerámicas de cuerda seca también se difundieron por algunas ciudades de la costa atlántica como Mértola y Cascais ${ }^{26}$, sin embargo, la gran incógnita es conocer los alfares que produjeron estas piezas y las relaciones comerciales para averiguar cuál fue el centro alfarero que les abasteció.

\section{Período almohade y NAzarí}

Entre los pocos hallazgos localizados en este período destacamos los de Ceuta (C. Posac, 1960:233) clasificado como meriníes. Para Posac estas piezas de cuerda seca presentan una extraordinaria analogía con las recuperadas en otros yacimientos andalusíes ${ }^{27}$ contemporáneos situados dentro de las fronteras del entonces reino de Granada. En este sentido, lo único que hemos localizado son jarros o fragmentos de los mismos en la Alambra, realizados con cuerda seca parcial y fechados entre los siglos XIII y XV (Martínez, 1991:75).

\section{Baja Edad Media}

Dos son las ciudades de la actual región andaluza, Almería y Málaga, que continúan produciendo cuerda seca ininterrumpidamente hasta el siglo XIV. Sin embargo, la producción parece que se extingue en este marco cronológico. Probablemente esté asociado al traslado de alfareros. Los hallazgos relacionados con estas fechas -entre los siglos XIII y XVpertenecen, en cambio, al Reino de Granada. Numerosas jarras o fragmentos de ellas se recuperaron en la Alambra (Martínez, 1991:75), aunque no sabemos si se trata de una producción local o es fruto de la actividad comercial. En cualquier caso, son testigos de la continuidad de la producción de cuerda seca. ¿Qué ocurrió con los alfareros que producían en estas ciudades? ¿Se trasladaron hacia Murcia y Valencia como ocurrió con las producciones de loza dorada? ${ }^{28}$ ¿O hacia el interior, hacia Toledo?

La historiografía ya señaló a Toledo, a principios del siglo XIX, como uno de los principales centros de producción. Esta versión partió de un ceramólo-

26 En Portugal se ha registrado una jarra de cuerda seca en Mértola, fechada en los siglo XII y XIII (Martínez, 1991:55) y un fragmento en Cascais, asociado a los siglos XI y XIII (Cardoso y Rodrigues, 1987:575-580).

27 Otros yacimientos andaluces con presencia de cuerda seca han aparecido en la calle Larga y calle Lancería de la pro- go, el barón de Davillier, al describir dos piezas halladas por él en España, propiedad de D. J. de Goyano de Sevilla (Gestoso, 1904:115-117). Dedujo que se trataba de una producción toledana y en concreto de Puente del Arzobispo. Las piezas en cuestión iban decoradas en el anverso con un león heráldico, mientras que en el reverso llevaba pintada en manganeso la leyenda "P. Arzobispo", que el noble tradujo por la localidad toledana, identificándolas como las siglas del lugar de producción (González, 1933:110-111) (Ainaud, 1952:234) (Aguado, 1983:16).

Si bien es verdad que el referido ceramio con la leyenda "P. Arzobispo" sigue siendo un misterio, no lo es la abreviatura señalada por el barón, que se encuentra en una de las cerámicas conservadas en el Instituto Valencia de Don Juan de Madrid ${ }^{29}$, lo que nos lleva a pensar, en todo caso, que fue una libre interpretación de la procedencia de estos objetos por parte del francés al leer la abreviatura.

Entre los ejemplares de las colecciones como las del I. V. D. J., Martínez Caviró (1991:305) ha observado diferencias en el perfil y acabado de dos platos, sin vidriar en el reverso, lo que podría significar otro lugar de producción, proponiendo la autora la ciudad de Toledo como posible lugar de procedencia. No olvidemos que Soler Ferrer advirtió que algunas piezas valencianas de cuerda seca parcial de los siglos XII y XIII se caracterizaban por no llevar barniz blanco de estaño. Sin querer descalificar la propuesta de las especialistas creemos más fiable, en estos casos ambiguos, el análisis de las pastas de las piezas para salir de dudas. Es cierto que las diferencias tipológicas pueden acusar diferentes lugares de producción, pero no debemos olvidar que también pueden indicar tipos cronológicos diversos como consecuencia de la evolución de una producción en un mismo lugar.

Sin embargo, las únicas pruebas documentales, por el momento, para afirmar la producción de cuerda seca en Toledo, son las excavaciones. En este sentido sólo conocemos el testimonio de Aguado Villalba, quien afirma que en el palacio de Maqueda, aparecieron ciertos fragmentos de piezas de vajilla que podrían demostrar la continuidad de la producción entre los siglos XII y XIV. Apoyando

vincia de Cádiz, fechados por comparación con otras piezas catalogadas entre los siglos XIII y XV (Montes y González, 1987:106).

28 Ver Sosa, 2004:21-41.

${ }^{29}$ I. V. D. J. a partir de ahora. 
esta posible afirmación Martínez Caviró ilustra un plato, de posible procedencia toledana, con decoración de estrella de doce puntas, fechado en torno a 1500 (Martínez, 1991:306. Fig.346).

En las últimas décadas, han ido saliendo a la luz tímidamente algunos vestigios de cuerda seca toledana. Por el contrario, las excavaciones realizadas en Puente del Arzobispo no han aportado pruebas de una posible producción de estas labores en la ciudad castellana (Martínez, 1991:299), así que, por el momento, tampoco contamos con documentos arqueológicos que apoyen la versión que propuso Davillier.

La segunda ciudad por excelencia a la que se ha atribuido la producción de cuerda seca ha sido Sevilla. El autor que ha defendido el origen hispalense ha sido José Gestoso y Pérez (1904:113). En su publicación señaló preferentemente su origen, así como la cronología de la mayor parte de las piezas de cuerda seca, como procedentes de esta ciudad andaluza.

Si recurrimos, una vez más, a los ejemplos conservados en museos y colecciones, vemos que tradicionalmente se les ha adjudicado a las cerámicas de cuerda seca un origen sevillano. Hasta ese momento, los únicos vestigios eran dos botes de farmacia provenientes del Hospital de la Sangre en Sevilla, hoy conservados en el Museo de Artes y Costumbres Populares de esta ciudad y en el Museo del Louvre en París, respectivamente, fechados hacia el año 1500 (Martínez, 1991:300), además de algunos azulejos que trataremos más adelante, realizados con esta técnica. Como muchas de estas piezas no están contextualizadas necesitamos recurrir a las excavaciones arqueológicas para confirmar su fabricación a los análisis de pastas.

Para el estudio de series como la loza dorada ${ }^{30}$ contamos con una amplia documentación que nos ayudó a determinar las zonas de producción. Por el contrario, en esta serie nos encontramos una gran laguna respecto de la denominación de esta técnica y de sus maestros, documentos que siempre nos ayudan a dilucidar las áreas de dedicación.

Ya adelantamos que Gestoso y Pérez, junto a las pruebas que aportaba para demostrar su teoría, añadió un documento procedente del Archivo de la

30 Ver Sosa, 2004:21-41.

31 Autores como Ainaud de Lasarte (1952:233) consideran esta denominación dudosa, pues en 1558 ya se realizaba plenamente la técnica de arista o cuenca. Gómez Moreno, a su vez, opina que el documento podría aludir al tema del lazo, típico de la ornamentación hispano-morisca más que a la técnica de cuerda seca propiamente dicha.
Catedral de Sevilla, en concreto del "Libro de Cargo y Data" y en cuyo texto dice que consta pagado en 1558 a Roque Díaz "por 550 holambres de azulejos y 74 alizares y 52 azulejos de cuerda seca y por 24 verduguillos que hasta oy se han traído para el solado de la pieça para la librería..." (Gestoso, 1904:55 y 400; Lubià, 1973:19) queriendo con ello sumar un testimonio de la fabricación de los azulejos de esta técnica en la ciudad hispalense. Sin embargo, el documento no sirve para aclarar si la técnica fue o no originaria de la ciudad de Sevilla.

Haga referencia o no a la industria que estamos tratando $^{31}$, el conjunto del documento alude a términos de elementos arquitectónicos y no a la técnica sobre los recipientes de vajilla o de uso cotidiano. El único argumento que creemos válido, por parte de Gestoso, es que en Sevilla se usó esta técnica sobre los azulejos y que es probable que la emplearan con anterioridad en las piezas de vajilla. Actualmente, según afirma Alfonso Pleguezuelo (1997:357), queda corroborada su elaboración gracias a los datos arqueológicos en cuyas piezas se observan motivos idénticos que decoran los platos en los reversos de los azulejos sevillanos, con lo que prueba que se realizaron en los mismos tallares.

A pesar de todo, desde entonces se ha aceptado, por la mayoría de los investigadores, la ciudad hispalense como el lugar de manufactura más importante de la cerámica de la cuerda seca en época de los Reyes Católicos (Lister \& Lister, 1987:114) (Martínez, 1991:266) (Pleguezuelo y Lafuente, 1995:228), y cuyos orígenes de producción parten desde las primeras Taifas (Pleguezuelo, 1985:19).

El Descubrimiento del Nuevo Mundo supuso un cambio de rumbo en la navegación y, por tanto, de los intereses comerciales. La existencia de fragmentos de cuerda seca en territorio americano ${ }^{32}$ nos permite ampliar el radio de dispersión de la serie cerámica por los yacimientos arqueológicos colombinos y demostrar, por tanto, la continuidad de su fabricación en los primeros años del siglo XVI gracias al estudio de algunos asentamientos bien fechados.

Sin embargo esta producción no sobrepasará la segunda mitad del siglo XVI, como se manifiesta en otros yacimientos asociados a la reapertura de la navegación atlántica como es el emplazamiento

32 Conocemos la existencia de un plato de cuerda seca recuperado en Santo Domingo, fechado a principios del siglo XVI (Deagan, 1987:55), así como varios hallazgos en los yacimientos de La Caleta y La Vega Vieja (República Dominicana) asociados a horizontes del siglo XVI (Goggin, 1968:28-31) 
marroquí de Alcácer Seguer (Redman \& Boone, 1979:5-75) $)^{33}$, a los que habrá que sumar, a partir de ahora, los ejemplos que hemos hallado en las excavaciones del Archipiélago Canario.

\section{LOS AZULEJOS DE CUERDA SECA}

Como han señalado la mayoría de los autores, la técnica de cuerda seca se aplicó primero sobre las piezas de vajilla y luego se empleó sobre las losetas arquitectónicas para simplificar los complicados alicatados (Aguado, 1979) (Sánchez, 1981:96-97) (Aréchaga, 1986:409-413) (Pleguezuelo, 1989:2126).

Partiendo de esta premisa, hemos de profundizar sobre los lugares en los que se recurrió al barro vidriado como decoración arquitectónica.

El barro vidriado se utilizó tímidamente en los exteriores durante el período almohade, alcanzando un gran esplendor en la etapa nazarí, sobre todo en el interior de los palacios, decorando zócalos y solerías (Martínez, 1991:95). En esta primera época almohade constituían verdaderos mosaicos elaborados por pequeñas piezas que los albañiles cortaban de placas y losetas monocromas y yuxtaponían sin más separación que el corte trazado.

Ya en el siglo XIV se va a desarrollar la lacería compuesta de cintas blancas rellenando los espacios poligonales con las piezas de colores. Esta producción es de tal complejidad que no es extraño que con el tiempo fuera sustituida por los azulejos de cuerda seca, tratando la decoración de la misma manera que se hacía sobre las piezas de vajilla y consiguiendo el mismo efecto decorativo. El dibujo completo del zócalo, o elemento arquitectónico concreto en el que se empleara la técnica, venía dado por la sucesión repetitiva de los azulejos formando un dibujo continuo (Sánchez et al, 1981:96-97).

33 En este yacimiento se localizaron 32 fragmentos de vasijas pertenecientes a platos y formas cilíndricas -quizás albarelos- en los niveles más altos de la ocupación islámica (Redman \& Boone, 1979:5-75).

34 Ejemplos de azulejos de cuerda seca, con decoración de lacería de raíz musulmana del siglo XV son los de la Capilla del Palacio de los Marqueses de Tarifa, conocida como Casa Pilatos, en Sevilla. También se conservan los azulejos del zócalo de las respectivas capillas de los palacios de los Duques de Alba y de los duques de Medinaceli, en la misma ciudad (Gestoso, 1904:109-110). Unos azulejos procedentes del Alcázar de Sevilla, hoy perdidos, completarían las armas de los monarcas Católicos (Martínez, 1991:268).

35 Ejemplos de conjuntos de cuerda seca fechados en el siglo
Si los siglos XI y XII fueron testigos de la proliferación de la industria sobre las piezas de vajilla, el siglo XV está asociado a su desarrollo sobre los azulejos. En cualquier caso para demostrar cuáles fueron las ciudades que produjeron estas piezas arquitectónicas debemos analizarlas teniendo en cuenta a las de tradición alfarera cuya destreza dominaban sobre las piezas de vajilla.

Desde el punto de vista cronológico los hallazgos más antiguos conocidos pertenecen a Granada, que es donde se encuentra el primer conjunto datado de azulejos de cuerda seca. Se trata de las albanegas de la Puerta del Vino de la Alambra (13661391) (Pleguezuelo, 1997:352) (Martínez, 1991:106 y 266).

Investigando sobre los lugares en los que se conservan paneles con azulejos de cuerda seca o excavaciones arqueológicas que nos ayuden a averiguar los lugares de producción, vemos que muchos de los edificios sevillanos atesoran estas labores, fechados en el siglo $\mathrm{XV}^{34}$, pero que por otros vestigios arquitectónicos fue un género que permaneció vivo hasta los primeros años de la segunda mitad del siglo $\mathrm{XVI}{ }^{35}$.

Sin embargo existen otras zonas que elaboraron azulejos de cuerda seca. Entre ellas Toledo, que fue un centro netamente musulmán hasta finales del siglo XIV y que será a partir de esta época cuando empiece a introducir elementos góticos en la decoración, pasando a especializarse en azulejería (Pleguezuelo, 1989:22).

Esta posibilidad ya se barajaba en los estudios realizados por Ainaud de Lasarte (1952:234) o José Aguado Villalba, confirmado posteriormente por Alfonso Pleguezuelo (1997:357) ${ }^{36}$. Aguado (1979:8) afirmaba que la producción de azulejos de cuerda seca y arista en Toledo existía desde finales del siglo XIII hasta mediados del siglo XIV, citando

XVI son dos azulejos por tabla conservados en el Convento de Santa Paula (Sevilla), uno en la clausura y otro en un patio exterior, integrados cado uno por tres azulejos. En la iglesia del mismo convento hay un escudo del sepulcro de León Enríquez elaborado con la misma técnica. Dos azulejos por tabla con el escudo de la familia Zapata y Chaves enmarcados con cuernos de la abundancia de clara tendencia plateresca, hoy en el I. V. D. J. (Martínez, 1991:268270).

36 Este autor está de acuerdo en que hubo una duplicidad en la fabricación, afirmando que las piezas son fácilmente identificables por el color de la pasta, más pálido el de Triana, por la delicadeza de las piezas y la mayor brillantez de los colores. 
incluso algunos ejemplos expuestos en el Museo Lázaro Galdiano de Madrid como procedentes de esta ciudad castellana.

A esto hay que sumar, que la difusión de la técnica de azulejos de cuerda seca en Toledo se produjo a partir de la segunda mitad del siglo XV, prolongándose su uso en buena parte de la centuria siguiente (Martínez, 1991:312). Parece que en el último periodo convivieron con los de arista, existiendo algunos ejemplares de transición en los que están incluidas ambas artes. La técnica de arista ya se empleaba, según este autor, desde mediados del siglo XV y continuó elaborándose hasta el primer tercio del siglo XVII (Aguado, 1979:9), fabricándose simultáneamente, avanzado el siglo, con su sucesora: la técnica de arista (González, 1964:117).

Otro dato de interés para el caso de Toledo, es que a partir del siglo XVI empiezan a desvanecerse los nombres árabes entre los documentos estudiados, posiblemente relacionado con la aparición de la técnica de cuerda seca y arista introducidas en la ciudad castellana, con la consiguiente presencia de nuevos hornos (Martínez, 1991:306).

La destreza del alicatado se conoció también en los hornos levantinos aunque parece que no alcanzó la maestría de sus homónimas sevillanas. Sin embargo, la dificultad de elaborar estas artes daría lugar también, con el tiempo, a la utilización de la técnica de cuerda seca sobre los azulejos para sustituir los complicados alicatados. Según los estudios realizados, parece que en ciertas ocasiones utilizaron unos moldes para trazar el dibujo que dejaban rehundidas las líneas de los perfiles, falseando mucho más la producción. Dicha modalidad se usó, al parecer, en los hornos de Alfara de Alquimia, lugar de procedencia de los azulejos del palacio episcopal de Segorbe (Martínez, 1991:197198). Gracias a los hallazgos arqueológicos de los testares y hornos de Manises y Cárcer se puede afirmar que en el territorio valenciano, durante el siglo XVI, la azulejería reprodujo tanto la cuerda seca como la arista aunque con un acabado de peor factura (Coll, 2002:32).

En resumen, si para la primera etapa es difícil

${ }^{37}$ Ejemplos de azulejos de cuerda seca se registran en Portugal, en concreto en el Palacio Nacional de Sintra, fechados en a finales del siglo XV, y en la iglesia de Santa una atribución de los fragmentos a una zona de producción original, entre las que conocemos al menos los testares de Badajoz y Toledo, la adscripción de los alfares del siglo XV es algo más confusa, por la falta de excavaciones sistemáticas que ayuden a datar estas labores en las zonas donde tradicionalmente se ha asignado esta fabricación; al menos para las piezas de vajilla, no así para la de los azulejos que alcanzaron una gran difusión desde la Baja Edad Media, en Sevilla, Toledo y Valencia. Con ello queremos decir que, aunque Triana sea uno de los centros de producción más importantes del siglo XV, -suponiendo que la mayor parte de las piezas conservadas en el I. V. D. J. y en el Museo Arqueológico Nacional son de esta procedencia- (Aréchaga, 1986:409), para las manufacturas anteriores o para descubrimientos de otros yacimientos no se debe descartar la presencia de ejemplares de otros posibles alfares peninsulares asociados a la tradición musulmana.

Todos estos datos son sumamente importantes porque quiere decir que allí donde existieron alfares y alarifes especializados en esmaltes de colores, eran lugares donde se podían elaborar trabajos de cuerda seca. Por eso, al hablar de los distintos focos de producción observamos que están relacionados con las zonas de mudejarismo peninsular, y que, probablemente, Sevilla fue el centro más especializado.

Desde el punto de vista cronológico esta producción no irá más allá del primer tercio del siglo XVI. El declive se debe a dos motivos fundamentales; por un lado, a la aparición de la técnica de "cuenca o arista" y de los azulejos llamados "pisanos", para la decoración arquitectónica; y, por otro, a la abundante llegada de cerámica de importación, con lo que terminará por imponerse en España, al igual que en el resto de Europa, el gusto renacentista en las vajillas (Gestoso, 1904:56) (Pleguezuelo, 1985:50-72). Sin embargo hasta estas fechas sigue la comercialización de estos objetos con la vecina Portugal ${ }^{37}$ lo que demuestra las constantes relaciones comerciales de producción alfarera que nos ayudará a constatar las relaciones políticas de ambos países, pero su estudio será abordado en un próximo trabajo.

María do Castelo (Abrantes) (Gestoso, 1904:268) (Pleguezuelo, 1997:353). 


\section{CARACTERIZACIÓN DEL MATE- RIAL RECUPERADO EN EL CON- VENTO DE SAN FRANCISCO DE ASIS DE LAS PALMAS DE GRAN CANARIA}

Tradicionalmente se ha hablado, desde el punto de vista cronológico, de dos momentos diferentes de producción para la cuerda seca en la Península: el primero durante el Califato y el otro a partir de la segunda mitad del siglo XV. Hoy se comprende que no hubo ruptura en su elaboración. Este último dato no podemos dejarlo pasar porque cabe la posibilidad de la presencia de este tipo de labores en yacimientos canarios, llegados a nuestras costas antes de la conquista. Y son estas fechas las que nos interesan para catalogar el material recuperado en el antiguo Convento de San Francisco de Asís de Las Palmas de Gran Canaria, pues fue cuando tuvo lugar la fundación del cenobio. Por tanto, ¿qué centros estaban funcionando en el siglo XV que pudieron proveer al cenobio grancanario?

Vimos que uno de los centros que produjo cuerda seca desde muy temprano, fue Badajoz, aunque no podemos considerar este alfar como posible lugar de procedencia pues el arrabal había desaparecido en 1113. Si bien es muy difícil determinar el origen de las obras conservadas en colecciones como las del Señor Osma o las del Conde de Valencia de don Juan, por no estar ligadas a un contexto arqueológico preciso, queremos señalar un dato muy sugestivo sobre las piezas de ambos coleccionistas. Se trata de un documento en donde se menciona que hay algunos ejemplares de cuerda seca adquiridos en Sevilla pero "dicese proceden de Extremadura" (Gestoso, 1904:119). Dato harto interesante si consideramos la conocida existencia del testar taifa de Badajoz y su producción de cuerda seca, lo que podría indicar la continuidad de la fabricación en otra zona de Extremadura fruto del traslado de alfareros como ha ocurrido en otros territorios de la península a lo largo de la historia y que, por el momento, nos es desconocida.

Pero ¿qué otras localidades producen cerámica de cuerda seca entre los siglos XIV y XVI? Por los hallazgos analizados, vemos que entre las ciudades que elaboran cuerda seca ininterrumpidamente, al menos desde el siglo XIV, y apoyándonos en las fechas valoradas por sus investigadores, tenemos

38 En cuanto al barro empleado, desde época musulmana, se manipulaban dos tipos de tierras. Para el caso de los azulejos sevillanos se utilizaba el de la Vega de Triana, mezclado
Málaga y Almería, demostrado por análisis de pastas, así como Toledo, Valencia y Sevilla. Otras ciudades en las que se ha localizado este producto son Murcia, Lérida y Granada. Por tanto, desde cualquiera de estas ciudades se pudo proveer al Archipiélago Canario. Pero centrándonos en el convento grancanario de San Francisco de Asis debemos fijar nuestra atención a partir de la fecha de fundación del convento y de los centros que mantenían esta producción.

Para contestar a la pregunta de cuál fue el centro productor de la cerámica de cuerda seca hallada en el cenobio franciscano y en qué fecha, -después de analizar los hallazgos catalogados en las colecciones y museos a los que hemos podido acceder, y de recurrir a otros vestigios salidos a la luz a través de las excavaciones contextualizadas-, hemos intentado obtener posibles paralelos a través de la comparación de las pastas con las que fueron elaboradas, de las formas y perfiles análogos, y, por último, a través de la tendencia estilística aplicada, no sólo desde el punto de vista de la técnica utilizada, sino también por el color empleado y el diseño ejecutado.

Considerando las ciudades que produjeron cuerda seca a partir del siglo XV, tenemos que los ejemplares franciscanos podrían ser toledanos, sevillanos o valencianos.

Como no se han hecho análisis ceramológicos a los fragmentos y muchos están descontextualizados, hemos recurrido a las descripciones que los investigadores han aportado para cada región en el campo cerámico.

Una de las pistas para diferenciar unas producciones de otras es, sin lugar a dudas, la pasta. En este sentido todos los fragmentos recuperados, tanto las piezas de vajilla como el azulejo, han sido elaborados con una pasta de color amarillo cremoso, de desgrasante no visible y de textura porosa ${ }^{38}$. Si utilizamos este criterio de selección los ejemplares franciscanos serían indudablemente sevillanos, pues parece que las piezas de Toledo se elaboraron con un barro de tonalidad rojiza, mientras que las de Badajoz se caracterizan por una tonalidad anaranjada y rosadas las valencianas.

El segundo criterio de selección es la morfología o perfil de las piezas, comparándolas con las series establecidas por los autores en las distintas regiones que produjeron cuerda seca.

con el de la Cuesta de Castilleja, y después de un proceso de preparación, se le añadia un puñado de lima, esto es, una especie de barro arenoso (Gestoso, 1904:61-62) 


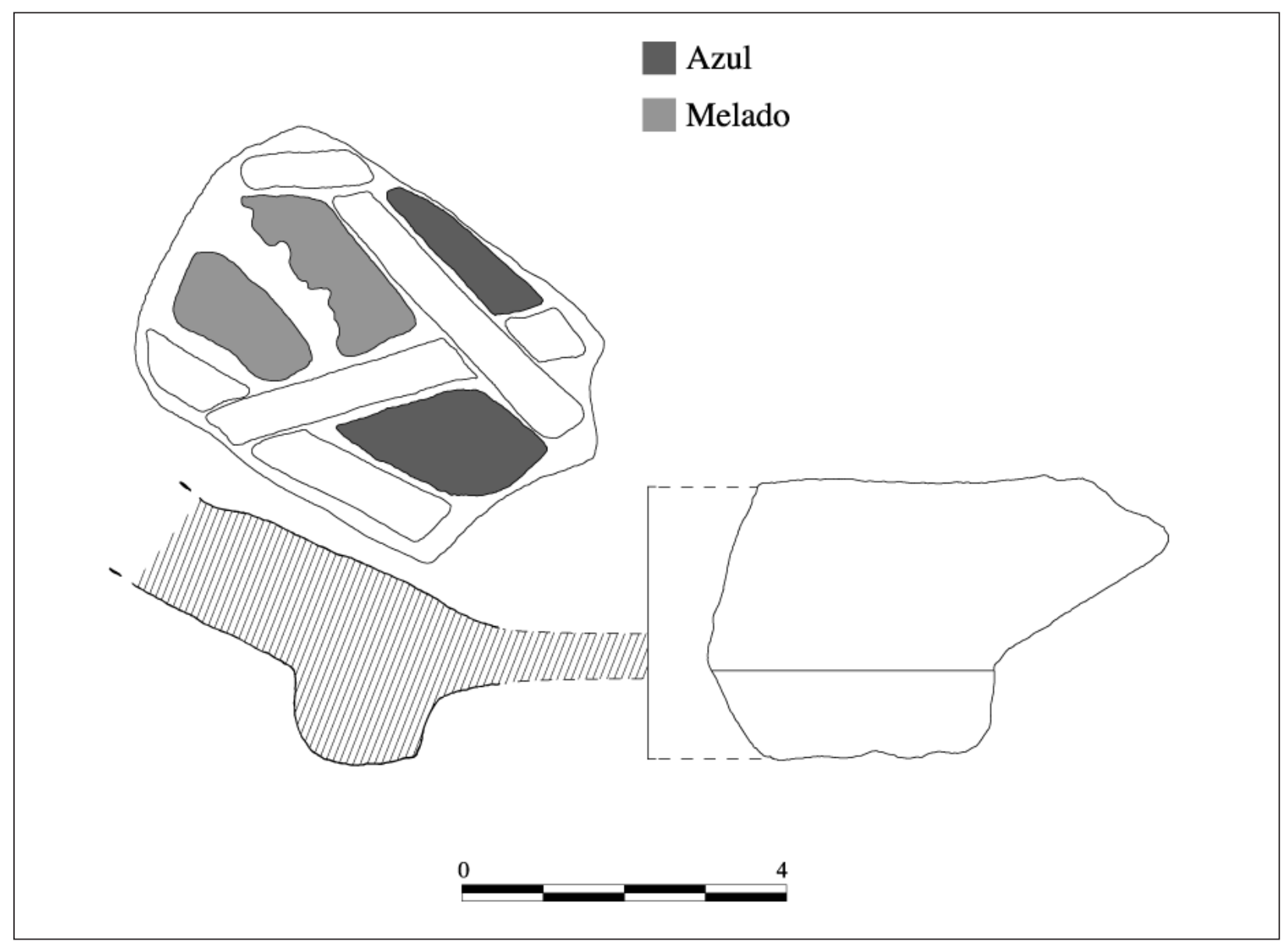

Figura 2. Base con pie en anillo, probablemente de una escudilla de cuerda seca.

\section{LA TIPOLOGÍA}

\section{Formas de vajilla: Platos y escudillas}

En la excavación del solar del antiguo Convento de San Francisco de Asís de Las Palmas de Gran Canaria, fueron registrados cinco fragmentos realizados con técnica de cuerda seca. Todos pertenecen a piezas de morfología abierta, pues la decoración se desarrolla en la cara interna de los recipientes. Los pedazos formaron, probablemente, parte de platos y escudillas. El hecho de que los mejores conservados sean paredes, hace imposible adivinar cuál fue la forma original de los ceramios y establecer, por tanto, una tipología de referencia.

Junto a un borde recto de labio redondeado y una pared cóncava, destacamos una base con pie en anillo (figura 2) que formó parte probablemente de una escudilla. Sólo podemos decir que coinciden con el repertorio tipológico general conocido para la cuerda seca en las colecciones existentes sobre este tipo de piezas, en las que abundan los platos planos con ligera convexidad central, decorados en el anverso y con reversos simplemente esmaltados en blanco.
No contamos con formas cerradas entre los fragmentos recogidos; menos frecuentes en las colecciones, sin embargo, destacan algunos jarros y albarelos expuestos en el I. V. D. J. de Madrid y en el Museo Arqueológico Nacional, decorados con esta técnica.

\section{Elementos ARQUITECTÓNICOS: LoS AZU- LEJOS}

Otro de los soportes a los que se aplicó la cuerda seca fueron los azulejos. Si bien en el cenobio franciscano hemos localizado un ejemplar incompleto, existen formas cuadradas y rectangulares en los catálogos generales.

\section{LA DECORACIÓN}

\section{LACERÍA}

Las piezas registradas con los $\mathrm{n}^{\circ} 22502$ (figura 3) y 24283, están decoradas con cintas blancas entrelazadas y cuyos espacios vacíos se rellenan con vedrío melado y azul. El lazo morisco es el tema más fre- 


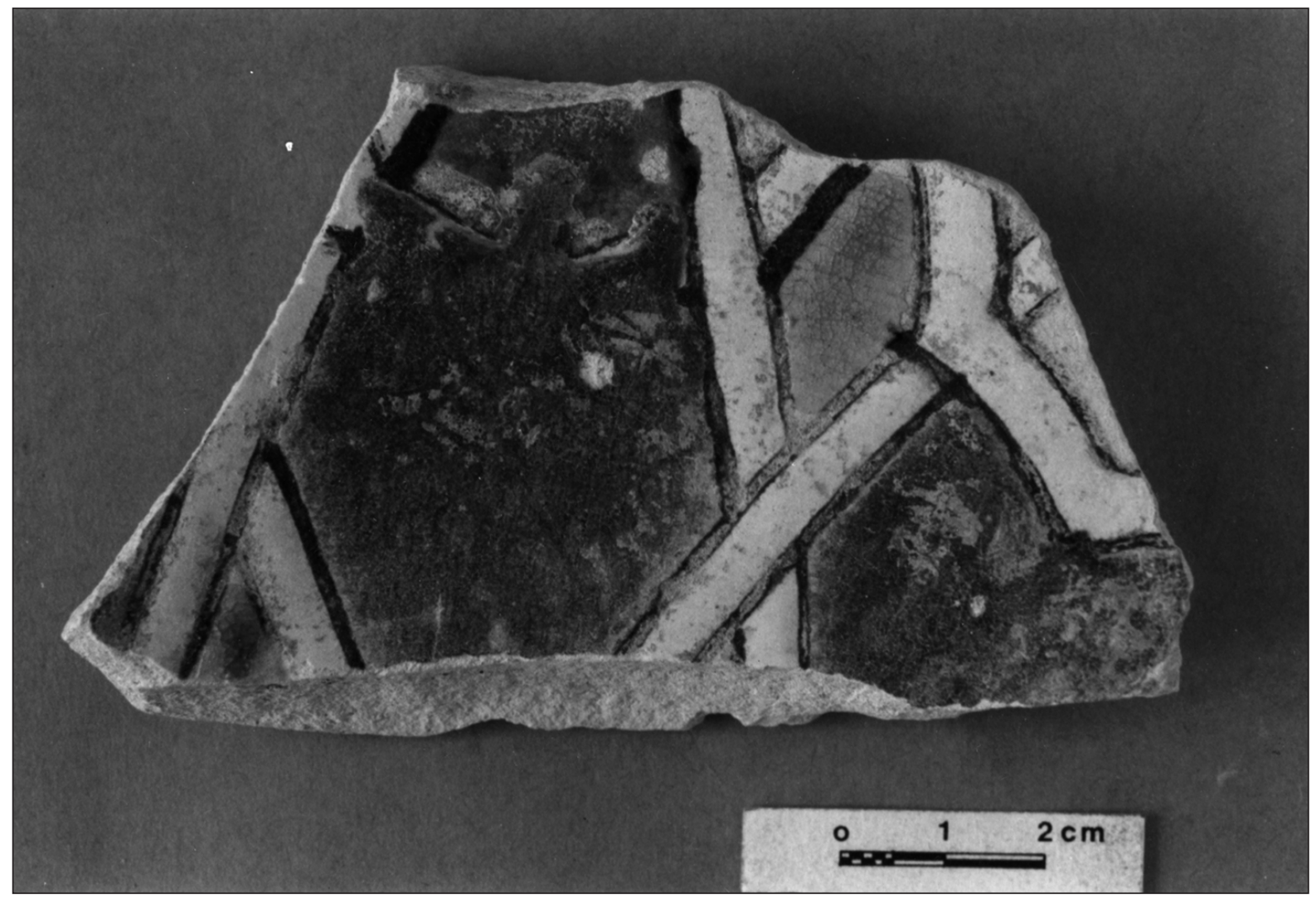

Figura 3. Fragmento de pared cóncava con decoración de lacería.

cuente en Sevilla, que alterna con la fauna, con figuras humanas o con temas heráldicos (Ainaud, 1952:233-238). Todos ellos son también comunes en la ciudad hispalense, además de los estrellados y los temas florales esquematizados (Martínez, 1991:198).

Hemos localizado solamente un fragmento de azulejo de cuerda seca que hemos registrado con el $\mathrm{n}^{\circ} 22472$. El motivo representado es el típico de lacería. En este ejemplar se puede ver la influencia islámica en las cintas estrelladas, esmaltadas en blanco, que rodean los espacios cubiertos de vidriados azules y melados. En los catálogos generales sobre la azulejería de cuerda seca se representan animales que pueden ser reales o quiméricos, sobre fondo florales; otras veces son inscripciones en caracteres cúficos o góticos (Aréchaga, 1986: 409). En casi todos los casos se representa un motivo único por azulejo, pero lo más común es que varios azulejos formen un florón al ensamblar cuatro de ellos, estableciendo redes poligonales, que normalmente se utilizaban en estancias suntuosas (González, 1964:117-118).

Nuestro fragmento, por el contrario, va simplemente decorado con las cintas blancas entrelazadas, sin ninguna ornamentación o representación gótica adicional. En este caso hemos encontrado un parale- lo idéntico en la Colección Carranza (Pleguezuelo, 1996:30), lo que nos ha permitido reconstruir el dibujo completo original (figura 4). Descrito como azulejo de cuerda seca mixta, al que se le da una cronología de finales del siglo XV. Las dimensiones del azulejo original son de $140 \times 140 \mathrm{~mm}$.

\section{DECORACIÓN GótICA}

Distinto es un fragmento de pared decorado con los colores tradicionales: blanco, azul, melado y negro, pero cuyo diseño está alejado de los esquemas de herencia musulmana que hemos visto entre los restos franciscanos. Consiste en unas líneas onduladas de color azul y melado, dispuestas alternativamente, junto a motivos indeterminados de color negro y blanco (figura 5). Todo hace pensar que se trató de un dibujo de pluma libre, pero que desgraciadamente no podemos reconstruir, ni hemos localizado paralelos entre las piezas consultadas en las diversas colecciones o museos.

$\mathrm{Si}$ las piezas de vajilla del siglo XV y comienzos del XVI, realizados con esta técnica, se consideran la síntesis del arte bajomedieval español del gótico y del renacimiento temprano (Martínez, 1991:299300), entre los restos arqueológicos del yacimientos de San Francisco tenemos una pequeña representación de ello. 


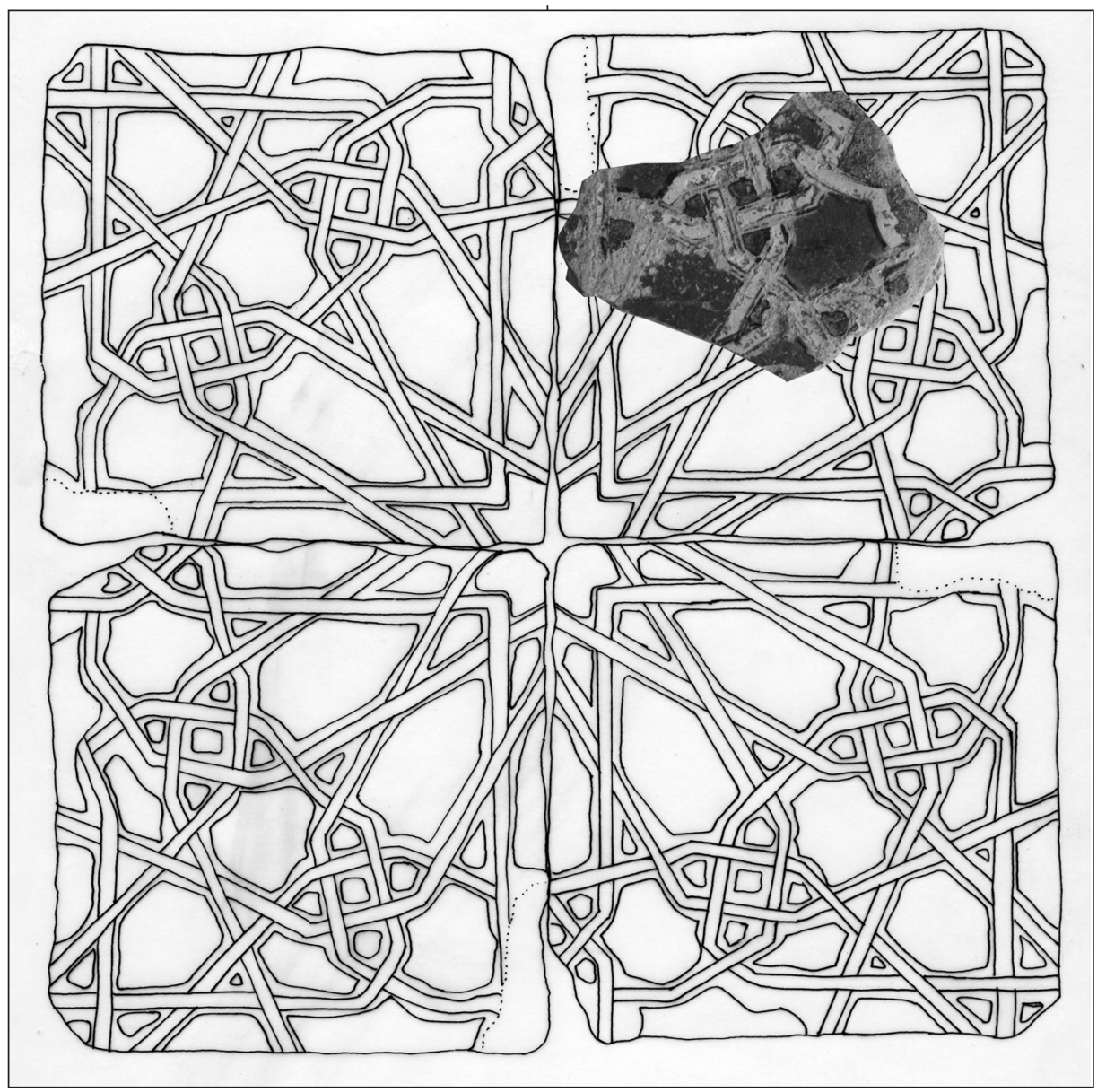

Figura 4. Reconstrucción del panel a partir de un azulejo de cuerda seca con motivos de lacería

\section{CONCLUSIONES}

Desde el punto de vista de la industria hubo una evolución en el proceso de elaboración. Si para la primera etapa, en la época de los Reinos de Taifas nos parece viable el proceso propuesto por Aguado Villalba, con el tiempo se perfeccionaría la técnica, llegando en la época de los Reyes Católicos a la fórmula descrita por la mayoría de los investigadores, es decir, la aplicación de una sustancia grasa para las líneas de manganeso y dos cochuras.

Aunque con todos los hallazgos queda demostrada parte de la producción y, sobre todo, la alta dispersión de cuerda seca en la Península Ibérica durante el Califato y las primeras Taifas, existió una continuidad en los períodos almorávide, almohade y nazarí. Sin embargo, quedan muchas intervenciones arqueológicas que realizar centradas en la localización de los posibles alfares de esta labor exclusiva, como fue la cerámica de cuerda seca, que nos permita comprobar el grado de especialización de algunas ciudades de tradición alfarera a lo largo de los siglos, llegando a su punto culminante en la época de los Reyes Católicos, etapa en la que alcanzó una gran maestría (Ainaud, 1952:233-236) (Martínez,
1991:56), así como establecer las redes comerciales de estos productos analizándolos a través de las tipologías y decoraciones y comprobándolo mediante análisis de pastas. Junto al estudio de aquella documentación que pueda arrojar luz sobre el traslado de alfareros en las distintas fechas de producción, unido, a las intervenciones arqueológicas que reflejen la sucesión histórica de los acontecimientos y más concretamente de la producción alfarera en cada una de las ciudades peninsulares.

Analizando la distribución espacial en el yacimiento canario de los escasos fragmentos recogidos, vemos que proceden de distintas cuadrículas y sectores de la excavación, en concreto en los cortes 24/36, 28/40, 40/40-40/24, 56/28, apareciendo, entre 10 y $40 \mathrm{~cm}$. de profundidad. Teniendo en cuenta que fueron excavadas en tallas artificiales de diez centímetros, poco o nada nos pueden ayudar para identificar la fecha de estas cerámicas recuperadas.

Desde el punto de vista de la función de estos recipientes, la producción de piezas de vajilla es escasa con respecto a la producción cerámica general, no sólo en el yacimiento franciscano, sino en otros peninsulares, al menos en aquellos casos en 


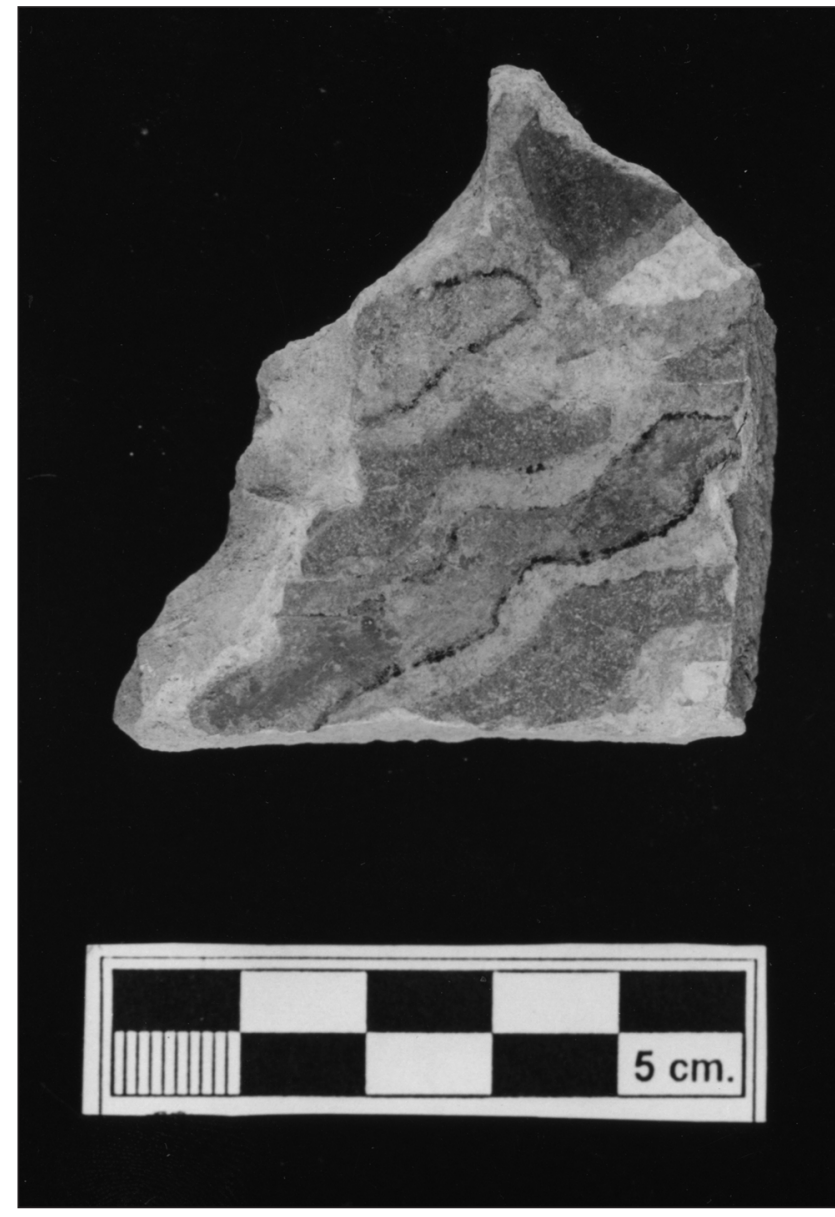

Figura 5. Fragmento de pared de cuerda seca con motivos ondulados.

los que los ejemplares se asocian al siglo $\mathrm{XV}$, por lo que a excepción de los botes de farmacia mencionados, las piezas de vajilla: escudillas, platos y jarras parecen tener una función decorativa dentro de las casas bajomedievales. Los Lister (1987:117) anotan la posibilidad de que formaran parte de un género privado en casas de alta sociedad. Si esto fuera cierto, en el caso del convento de San Francisco estarían más vinculados al hospedaje que al uso privado por parte de los franciscanos.

Si unimos los dos criterios anteriores cabe también la posibilidad de que estos fragmentos correspondan a material exógeno, trasladado hasta los sótanos del cenobio con el fin de colmatar el solar, y que por tanto no formaran parte de la vida del convento, sino del ajuar de alguna casa de la zona colindante. Desgraciadamente no sabemos desde dónde se transportó esta tierra para el relleno.

Los azulejos se destinaban indiscutiblemente a decorar los interiores de las edificaciones. Utilizados los de cuerda seca en zócalos y en olambrillas de pavimentos, según los ejemplos conservados, el único ejemplar recuperado, probablemente formó parte del zócalo de alguna estancia del convento, acompañando a los paneles decorados con azulejos de arista. En Sevilla es común ver frontales de altar o zócalos recubiertos de azulejos en los que se combinan ambas técnicas.

Como siempre la pregunta que nos hacemos es qué focos de producción y cuándo se elaboró este tipo de cerámica asociado a la vida del ex-convento franciscano, para intentar descubrir la ciudad productora, y en qué fechas abasteció al cenobio.

$\mathrm{Si}$ atendemos a los lugares de tradición cerámica podría ser tanto la región valenciana, toledana o andaluza. A su vez, apoyándonos en la documentación escrita vemos cómo, en el segundo momento de esplendor de este tipo, es decir, en la época de los Reyes Católicos, es Sevilla la gran productora, y que no sólo exporta material a otras ciudades, sino que incluso envía alarifes especializados en estos trabajos. Por tanto, aunque a lo largo de la Edad Media fueron varias las capitales que elaboraron cuerda seca, parece que en el siglo XV, fue la ciudad hispalense la especialista por excelencia, sin descartar otras localidades como Toledo.

Podemos concluir diciendo que los ejemplares hallados en el solar del antiguo Convento de San Francisco de Asís de Las Palmas pertenecen con toda seguridad a finales del siglo XV y los primeros años del siglo XVI, basándonos en la fecha de fundación del cenobio franciscano, así como por la vida que tuvo la técnica de cuerda seca en la Península, por lo que indudablemente pertenecen al segundo momento de apogeo, es decir a la época de los Reyes Católicos.

Por último, el predominio de los motivos decorativos totalmente mudéjares o góticos apuntan como probable lugar de producción a la ciudad de Sevilla, por estar alejados de los gustos renacentistas que empezarán a imponerse unas décadas después, y también por el tipo de pasta amarilla con que fue elaborada, al ser una característica de los alfares trianeros.

\section{AGRADECIMIENTOS}

Quiero agradecer este trabajo a don Antonio Tejera Gaspar y a don Eduardo Aznar Vallejo por su tiempo y buena disposición para corregir el texto y apuntar siempre acertadas sugerencias. A mis amigas Elyse Christian y Guadalupe Sánchez por su ayuda en la traducción del resumen a la lengua inglesa. A los técnicos de El Museo Canario por la ayuda y facilidades que me brindan siempre para realizar este y otros trabajos. 


\section{BIBLIOGRAFÍA}

ABELLÁN, J. et al (1986): “Cerámica hispanomusulmana de la provincia de Cádiz. Primeras piezas halladas en el yacimientos de Caños de Meca". II CICMMO, (Toledo, 1981), 141-148.

AGUADO VILLALBA, J. (1979): Los azulejos toledanos a través de los siglos. Toledo.

AGUADO VILLALBA, J. (1986): "Cerámica hispanomusulmana de Toledo". II C. I. M. M. O. (Toledo 1981), 127-134.

AGUILAR MOYA, L.; GONZÁLEZ RODRÍGUEZ, R. y BARRIONUEVO CONTRERAS, F. (1998): "El asentamiento pre-almohade de Jerez de la Frontera (Cádiz)" SPAL 7, 163-173.

AINAUD DE LASARTE, J. (1952): “Cerámica y vidrio". Ars Hispaniae X. Madrid.

ALMAGRO-BASCH, M. y LLUBIÁ MUNNÉ, L. M ${ }^{\mathrm{a}}$ (1952): “Aragón-Muel”. CERAMICA. Barcelona.

ALZOLA GONZÁLEZ, J. M. (1986): La iglesia de San Francisco de Asís de Las Palmas. Las Palmas de Gran Canaria.

ARÉCHAGA, C. de (1986): "Antecedentes de la loza de cuerda seca en Toledo en el siglo XV". II C.M. M. O. (Toledo 1981), 409-413.

BERTI, G. et al (1993): Naves andalusíes en cerámicas mallorquinas. Palma de Mallorca.

CARDOSO, G. e RODRIGUES, S. (1987): “Alguns tipos de cerámica dos séculos XI a XVI encontrados em Cascáis". Actas do IV Congresso A Cerámica Medieval no Mediterrâneo Occidental, 575-585.

CASAMAR, M. y VALDÉS, F. (1984): “Origen y desarrollo de la técnica de cuerda seca en la Península Ibérica y en el Norte de África durante el siglo XI". Al-Qantara vol V, 283-404.

CEBALLOS ESCALERA, I. (1966): "Cerámica española”. Catálogo de la exposición del Buen Retiro. Madrid.

CUENCA SANABRIA J. et al (1993): "La investigación histórico-arqueológica del desaparecido convento de San Francisco de Las Palmas de Gran Canaria". Investigaciones arqueológicas 4, 9-198.

DEAGAN, K. (1987): Artifacts of the Spanish Colonies of Florida and the Caribbean 15001800. Vol.1, Washington D. C.

ESTEVE GUERRERO, M. (1960): "Nuevo hallazgo de cerámica árabe en Mesa de Asta. Jerez de la Frontera". Al-Andalus XXV, 200-203.
FERNÁNDEZ GABALDÓN, S. (1987): “El yacimiento de la Encarnación (Jerez de la Frontera): bases para la sistematización de la cerámica almohade en el S. O. peninsular" Al Qantara VIII, 449 y ss.

GESTOSO y PÉREZ, J. (1904): Historia de los barros vidriados sevillanos desde sus orígenes hasta nuestros días. Sevilla.

GOGGIN, J. M. (1968): Spanish Majolica in the New World. New Haven.

GÓMEZ MORENO, M. (1924): Cerámica medieval española. Barcelona.

GÓNZÁLEZ MARTÍ, M. (1933): Cerámica española. Barcelona.

GONZÁLEZ MARTÍ, M. (1964): Museo Nacional de Cerámica "González Martí". Madrid.

LISTER, F. C. y LISTER, R. H. (1987): Andalusian Ceramics in Spain and New Spain. Arizona.

LOBO CABRERA, M. (1981): Aspectos artísticos de Gran Canaria en el siglo XVI. Documentos para su historia. Las Palmas de Gran Canaria.

LLUBIÀ MUNNÉ, L. Ma (1973): Cerámica medieval española. Barcelona.

MARÍN Y CUBAS, T. (1986): Historia de las siete islas de Canaria. Las Palmas de Gran Canaria.

MARTÍNEZ CAVIRÓ, B. (1991): Cerámica hispanomusulmana. Madrid.

MILLARES TORRES, A.: Anales de las Islas Canarias. T. V (1700-1749). Manuscrito. Archivo de El Museo Canario.

MILLARES TORRES, A. (1860): Historia de la Gran Canaria. T. I, Las Palmas de Gran Canaria.

MONTES MACHUCA, C. y GONZÁLEZ RODRÍGUEZ, R. (1987): "Excavaciones arqueológicas en el casco urbano de Jerez. Año 1987. Calle Larga 21-25 y Calle Lancería 3-7". Anuario Arqueológico de Andalucía T. III, 99-108.

MORALES PADRÓN, F. (1978): Canarias: crónicas de su conquista. Las Palmas de Gran Canaria.

NAVARRO PALAZÓN, J. (1986): La cerámica islámica de Murcia. Volumen I: Catálogo. Murcia.

PAETOW, F.: Canarias 7, 10 de abril de 1992, 53.

Periódico El Ómnibus $n^{\circ} 144$, Las Palmas, 17 de diciembre de 1856.

PLEGUEZUELO HERNÁNDEZ, A. (1985): Cerámica de Triana: siglos XVI-XIX. Sevilla.

PLEGUEZUELO HERNÁNDEZ, A. y LAFUENTE, 
Ma . P. (1995).: "Cerámicas de Andalucía Occidental (1200-1600)". Spanish Medieval Ceramics in Spain and the British Isles. BAR International Series 610, 217-244.

PLEGUEZUELO HERNÁNDEZ, A. (1996): Cerámicas de Triana. Colección Carranza.Sevilla.

PLEGUEZUELO HERNÁNDEZ, A. (1997): "Cerámica de Sevilla (1248-1841)" Summa Artis, vol. XLII. Cerámica española, capítulo IX, 344386.

POSAC MON, C. (1971): "La arqueología en Ceuta entre 1960-1970". Noticiario Arqueológico Hispánico XV, 227-235.

REDMAN, C L. \& Boone, J. L. (1979): “Qsar esSeghir (Alcácer Ceguer): A fifteenth and sixteenth century Portuguese colony in North Africa". STVDIA $n^{\circ}$ 41-42, 5-77.

RIBERA, A. y LERMA, J. V. (1984): "Panorámica de la arqueología urbana. Valencia romana e islámica. Revista de Arqueología, año V, $n^{o}$ 40, 37-44.

ROSELLÓ BORDOY, G. (1986): "Mallorca: comercio y cerámica a lo largo de los siglos X al XIV". II C. I. M. M. O. (Toledo, 1981), 193-203.

SÁNCHEZ-PACHECO, T. et al (1981): Cerámica esmaltada española. Barcelona. SESEÑA DÍEZ, N. (1982): "Cerámica (siglos XIII-XIX)".
Historia de las Artes Aplicadas e Industriales en España, 554-620.

SOLER FERRER, M P. (1989): Historia de la cerámica valenciana. T. III, Valencia.

SOSA SUÁREZ, E. (2004): "La cerámica de reflejo metálico del antiguo convento de san Francisco de Las Palmas de Gran Canaria”. Butlletí

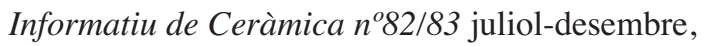
21-41.

TEJERA GASPAR, A. (2002): Colón en Gran Canaria (1492, 1493, 1502). Las Islas Canarias en las Fuentes Colombinas. Las Palmas de Gran Canaria.

VV. AA. (2002): Cerámica de Paterna. Reflejos del Mediterráneo. Valencia.

VV. AA. (2002): Lozas y azulejos de la Colección Carranza. Castilla-La Mancha. 